\title{
Getting the balance right? A mismatch in interaction demands between target and judge impacts on judgement accuracy for some traits but not others
}

\author{
H.J. Wall ${ }^{\mathrm{a}, *}$, Paul J. Taylor ${ }^{\mathrm{b}}$, C. Campbell ${ }^{\mathrm{c}}$ \\ a Edge Hill University,UK \\ ${ }^{\mathrm{b}}$ Lancaster University, UK \\ c Ulster University, UK
}

\section{A R T I C L E I N F O}

\section{Article history:}

Received 5 June 2015

Received in revised form 14 August 2015

Accepted 22 August 2015

Available online 10 September 2015

\section{Keywords:}

Interaction demand

Parallel process model

Impression management

Judgement accuracy

Interpersonal trait

Self-presentation

Evaluation expectation

Realistic accuracy model

\begin{abstract}
A B S T R A C T
The present study examined the role of target and judge interaction demands on first impression accuracy $(n=$ 195). Specifically, the role of targets' self-presentation concerns and judges' information processing demands on accuracy for interpersonal traits (i.e., traits likely to be accentuated within an interpersonal context) and less interpersonal traits (i.e., traits less likely to be accentuated within an interpersonal context) was examined. Pairs of unacquainted participants ( $n=88$; females $=52$, males $=36$ ) interacted for ten-minutes in one of three interaction conditions that sought to vary interaction demands by manipulating the degree to which participants were aware of judging and/or being judged. Accuracy was assessed by correlating judgements formed with a measure of target's personality that comprised an average of self-ratings and informant-ratings $(n=107)$. Findings revealed that in interaction conditions where there was a mismatch in evaluation expectations - when a participant knows he or she will judge but not that he or she will be judged - accuracy for "less interpersonal" traits is diminished. Findings are discussed in relation to Patterson's (1995) parallel process model of interpersonal communication and Funder's realistic accuracy model (1995). Limitations in terms of the generalisability of the findings are discussed.
\end{abstract}

(c) 2015 Elsevier Ltd. All rights reserved.

\section{Introduction}

People routinely judge the personalities of those around them, and the accuracy of such judgements can have important consequences impacting on who they choose to hire, collaborate with, trust and befriend (Funder, 1999). Personality research has examined the moderators of the validity of initial personality judgements (Back, Schmukle, \& Egloff, 2008; Beer \& Watson, 2008; Blackman \& Funder, 2002; Wall, Taylor, Dixon, Conchie, \& Ellis, 2013) and has shown that 'accuracy' or agreement between a judge's rating of a target and the target's personality score, is nuanced in terms of characteristics of the judge (Human \& Biesanz, 2012; Letzring, 2005, 2008), target (Akert \& Panter, 1988), the information on which a judgement is based (Letzring, Wells, \& Funder, 2006) and the specific trait in question (Gosling, Ko, Mannarelli, \& Morris, 2002). Although much substantive accuracy research is concerned with these moderators (see Funder, 1999) less literature has explored proximal influences such as interaction demands, motivation and 'forewarning' on 'real' interactions (cf. Hall

\footnotetext{
* Corresponding author at: Edge Hill Psychology Department, Saint Helen's Road, Ormskirk, Lancashire L39 4QP, UK.

E-mail address: helen.wall@edgehill.ac.uk (H.J. Wall).
}

et al., 2009). Forewarning targets and judges about their role within an interaction has begun to be examined in the communications and emotion literature (e.g., Ickes, Gesn, \& Graham, 2000) and the field of deception detection (Forrest \& Feldman, 2000); however, the role of target and judge interaction demands on the 'accuracy' of initial personality judgements has not yet been examined. The present study examines variations in target and judge interaction demands on Big-5 judgement accuracy.

\section{Importance of target and judge interaction demands}

Social interaction is complex and is not a passive process (Swann, 1984). Interaction typically involves managing our own behaviour whilst simultaneously making social judgements of others. The subtleties involved in this everyday task of being a target and a judge is captured in Patterson's (1995) parallel process model of communication. This model assumes that a person's social judgements and behaviours are parallel processes shaped by goals and expectancies (see also Patterson \& Stockbridge, 1998), therefore, our cognitive resources within an interaction are affected due to managing our own behaviour and impressions of another. Indirect evidence suggests that the impact of different interaction demands on perceptions is mixed. Specifically, there is evidence to 
suggest that the more impression management demands placed on people (the targets) the less accurate they will be when rating how their partner (the judge) perceives them (i.e., meta-perception; Patterson, Churchill, Farag, \& Borden, 1992). In contrast, research has reported enhanced interpersonal sensitivity when targets are instructed to 'try hard' to make an 'accurate' impression (Ickes et al., 2000; Keltner, Gruenfeld, \& Anderson, 2003) yet this accuracy was not examined from a trait perspective. Moreover, 'trying hard' may not always result in enhanced accuracy and has been shown to be moderated by relationship status (Snodgrass, 1985). Studies have concluded that judges instructed to be 'accurate' may overthink an automatic judgement process (Forrest \& Feldman, 2000; Klein \& Hodges, 2001) or withdraw effort and perform worse (Jamieson \& Harkins, 2007). Further indirect support for the importance of interaction demands on judgements comes from research reporting that power imbalances between target and judge interferes with information processing (Rodriguez-Bailon, Moya, \& Yzerbyt, 2000). Although none of these studies examined personality judgement accuracy the findings reveal the differential effects that interaction demands can have on judgements.

Indeed, Funder $(1995,1999)$ posits that an accurate judgement depends on good cue availability from a target combined with a judge noticing and correctly interpreting these cues. Thus, the question of what happens to judgement accuracy when targets are also judges, as is often the case in most everyday dyadic interactions (i.e., self-presenting whilst simultaneously judging others), is an interesting and open question.

In relation to personality judgements, self-presentation demands placed on targets may shape first impression accuracy in important ways. For example, consider two people, William and Jenny, on a first date: the cues that Jenny reveals arguably depends on the degree to which she seeks to manage her presentation. As intimated in the parallel process model of communication, the judge (i.e., William) is also important as the cues on which judges rely in such scenarios likely depends on the degree to which they are attending to these if the situation requires it. It is argued here that the interaction demands placed on targets and judges may shape targets' self-presentation efforts and judges' social information processing, and impact on 'accuracy'.

\section{Self-presentation and judgement accuracy}

Self-presentation (SP) concerns the regulation of one's behaviour so as to convey a specific impression to others (Baumeister, 1982; Schlenker \& Weigold, 1989). This presentation of self has also been referred to as impression management (IM) and Leary and Kowalski (1990) note that IM and SP are often used interchangeably, thus SP will be used synonymously with IM.

There has been a wealth of social psychological research into the construct of IM ranging from the tactics involved (Ellis, West, Ryan, \& DeShon, 2002; Gilmore \& Ferris, 1989) to the effects of target IM on perceivers' ratings of targets in terms of likeability (Bolino, Varela, Bande, \& Turnley, 2006) and attitudinal evaluations (Snyder \& Swann, 1976). Research has also examined impressions of targets based on the targets' IM attempts in terms of what they do (e.g., specific tactics) (Kacmar, Carlson, \& Brymer, 1999; Leary \& Kowalski, 1990), and the impact of motivation on impression formation in terms of gender stereotypes (Rudman, 1998; see also Vohs, Baumeister, \& Ciarocco, 2005). The question of whether the target person engaging in SP is accurately perceived in terms of their personality traits remains unanswered (cf. Biesanz \& Human, 2010). Specifically, although research examining how targets engaging in IM fare socially is useful in terms of increasing our understanding of the social processes surrounding IM (i.e., how we judge), it is also necessary to understand when IM impacts on accuracy hence the present focus on target and judge interaction demands. This is important for at least two reasons. First, an increased understanding of when interaction demands may shape accuracy is practically important and may inform the planning of interview practices or remote assessments. Second, a focus on target and judge interaction demands will enhance our understanding of social information processing from an accuracy perspective as research has exclusively examined either the target being judged or the demands placed on the judge. The major objective of the present study, therefore, was to explore the role of target and judge interaction demands on judgement accuracy across situations that varied in terms of judges 'knowing' or 'not knowing' that a judgement is required about the target and in terms of targets 'knowing' or 'not knowing' that they will be judged after engaging in a ten-minute getting acquainted interaction.

Studies examining first impression accuracy tend to report increased accuracy for the more "interpersonal traits" such as extroversion relative to the less interpersonal traits (and those subject to IM concerns) such as neuroticism (Albright, Kenny, \& Malloy, 1988; Funder \& Colvin, 1988). These findings are typically explained in terms of properties of the trait itself; whereby traits such as neuroticism are difficult to judge on the basis that there are less overt cues on which to base judgements (Funder \& Dobroth, 1987; Funder \& Colvin, 1988) whereas extroversion is known as a visible trait with numerous cues available to judges. Another plausible, and related explanation, is that the differences in accuracy by trait type relate to targets' concealing the more negative aspects of self and accentuating the more positive aspects of their personality (i.e., fake good, fake bad: Barrick \& Mount, 1996; Ones \& Viswesvaran, 1998). A number of findings are consistent with this contention. Barrick and Mount (1996) focused exclusively on the less interpersonal traits of neuroticism and conscientiousness and reported evidence of IM. In Gill and Oberlander's (2003) study investigating personality perception based on an email, they conclude that authors of an email appear to linguistically conceal aspects of neuroticism relative to the interpersonal trait of extroversion. Similarly, Paulhus, Bruce, and Trapnell (1995) demonstrated that conscientiousness may be susceptible to IM effects because people do not always feel able to act in line with their 'true' selves. Taken together, these findings suggest that targets' SP may shape accuracy in distinctive ways. Specifically, one might expect that interpersonal traits such as extroversion and agreeableness are likely to be judged more accurately when SP demands are high (i.e., self-enhancement) as targets will emit numerous cues about such highly observable and interpersonal traits whereas less interpersonal traits are likely to be judged less accurately when evaluation expectation demands are high as people may choose to conceal relevant cues from judges (i.e., self-deception) and such traits may be less relevant to a social interaction. Of course, as outlined in Section 2, there is reason to believe that the cues on which judge's focus may also vary in terms of trait type. Indeed, Ames and Bianchi (2008) assert that the relational context surrounding target and judge can shape the traits that judges focus on. In their study on supervisor-student judgements of each other they reported that students were more concerned with rating their supervisors' level of agreeableness whereas supervisors where more concerned with rating the students' level of conscientiousness.

To date, no study has directly examined the impact of different interaction demands and judgement accuracy in 'real life' contexts. Indirect evidence that targets engaging in SP may shape accuracy comes from Human, Biesanz, Parisotto, and Dunn (2012) who demonstrated that SP is positively associated with judgement accuracy. Although substantive, their study did not examine self-presentation concerns within an interaction nor differences across trait type. Another study by Murphy (2007) focused on how IM impacted on observers' ratings of effectiveness and found more positive impressions of intelligence for targets engaging in IM in addition to distinctive behavioural patterns. This study, however, did not examine judgements of personality; therefore, the current paper builds on this work and investigates whether different interaction demands shape accuracy.

\section{Current study}

In the present study, we sought to explore the role of judge and target interaction demands on personality judgement accuracy. Accordingly, a dyadic design was employed whereby each dyad member was 
both a target and a judge and interacted with each other for ten minutes in one of three conditions designed to vary interaction demands. Specifically, interaction demands of both target and judge were manipulated in terms of whether or not the target knows they are being judged and whether or not the judge knows that they will be asked to make a judgement of the target using three conditions: Condition 1: Judge Aware of Judging-Target Aware of being Judged; Condition 2: Judge Aware of Judging-Target Unaware of being Judged; and Condition 3: Judge Unaware of Judging-Target Unaware of being Judged. Extroversion and agreeableness were operationalised as interpersonal traits as numerous studies have reported these two traits as such (Funder \& Dobroth, 1987; Funder \& Colvin, 1988). Further support for this distinction comes from studies examining direct behaviours, which have found extroversion to be related to 'smiles' and 'initiating conversation' (Argyle, Martin, \& Crossland, 1989). Similarly, agreeableness has also been linked to smiling (Naumann, Vazire, Rentfrow, \& Gosling, 2009) and greater visual attention (Berry \& Hansen, 2000). In contrast, conscientiousness and neuroticism were operationalised as less interpersonal traits as these are arguably less likely to be accentuated within an interpersonal context (Gill \& Oberlander, 2003) and have been linked to behaviours less relevant to communication (e.g., tidiness of office; Gosling et al., 2002; being healthy looking; Berry \& Hansen, 2000). Using this dyadic design, the following hypotheses were tested:

H1. Accuracy will differ across contexts varying in interaction demands.

H2. Contextual variations in interaction demands will significantly impact on accuracy in terms of the type of trait being judged; interpersonal vs. non-interpersonal traits.

\section{Method}

\subsection{Participants}

195 participants (mean age $=20.83, S D=3.68$ ) were recruited of which 88 comprised the dyad members (i.e., target-judge pairs). Dyads ( $52=$ female, $36=$ male) were recruited through the University's research participation scheme. Of this 88 , thirty participated in a 'Judge Unaware of Judging-Target Unaware of being Judged' condition, 26 participated in a 'Judge Aware of Judging-Target Unaware of being Judged' condition, and 32 participated in a 'Judge Aware of Judging-Target Aware of being Judged' condition. Participants were randomly paired with their interaction partner. The self-reported ethnicity of these participants were $82 \%$ White British, $14 \%$ Asian, $2 \%$ Black African, and $2 \%$ Other. Dyad members were asked to nominate somebody they knew well to provide additional ratings of their personality. These nominated others comprised the remaining informants ( $n=$ 107 ) (e.g., friends or family of each dyad member) who provided their ratings using postal questionnaires. Inclusion criteria for participants excluded people who had a previous acquaintance with their interaction partner.

\subsection{Materials}

\subsubsection{Personality measure}

All participants rendered judgements of Big- 5 personality traits using a 50-item questionnaire derived from the International Personality Item Pool (IPIP, Goldberg et al., 2006). Specifically, participants responded to 5 sets of 10 items measuring extraversion, neuroticism, conscientiousness, openness, and agreeableness. For each item, they were asked to rate the extent to which the statement described themselves, or the person that they were rating, from 1 (Extremely Inaccurate) to 7 (Extremely Accurate). The IPIP measure is widely used (e.g., Ashton \& Lee, 2005) and demonstrates good construct validity (Buchanan, Johnson, \& Goldberg, 2005).
To avoid some of the problems inherent in self-reports of personality (e.g., socially desirable responding; Borkenau \& Liebler, 1992), ratings of target personalities were also obtained from knowledgeable informants (i.e., friends, family members) who knew the dyad member well. The average correlation between targets' self-ratings and informant ratings was .54 (range .34-.76), which is comparable with the correlations observed in previous research (e.g., Kurtz \& Putnam, 2006).

\subsubsection{Impression management}

Bolino and Turnley's (1999) IM scale was employed to measure five IM tactics: i) ingratiation or favour doing; ii) self-promotion, or emphasising abilities/accomplishments; iii) exemplification or going beyond the call of duty; iv) supplication or advertising shortcomings; and v) intimidation or appearing threatening. The measure used consisted of 23 items tapping the extent to which individuals engage in these IM behaviours, with responses ranging from 1 (Very Inaccurate) to 5 (Very Accurate).

\subsection{Procedure}

Unacquainted dyad members signed up for a study interested in 'language and personality' and they were scheduled to arrive at different rooms to ensure no prior acquaintance. On arrival, regardless of experimental condition, participants were informed that they would be completing some questionnaires about themselves and then interacting with another participant for $10 \mathrm{~min}$ in a café. They were further informed that the experimenter would not be present during their chat, and that they should talk about 'anything they wanted', which is consistent with previous studies (Letzring et al., 2006; Markey \& Wells, 2002). The use of a café sought to create a context that encouraged the expression of individual differences.

The three experimental conditions varied according to whether or not participants were informed (verbally and in writing) before their interaction that they would be asked to judge their partners personality. Regardless of which condition participants were assigned to all participants were asked to complete a personality questionnaire about themselves and engage in a ten-minute interaction with an unacquainted other. However, the crucial differences in pre-interaction instructions given to individual dyad members was in relation to whether or not they would need to judge their interaction partners' personality. In the Judge Aware-Target Aware condition (i.e., judge aware of judging and target aware of being judged), participants were informed before their interaction that, at the end of the interaction, they would be: i) taken to a separate room and asked to provide a judgement of their interaction partner's personality; and ii) that their interaction partner would also be rating them. In the Judge Aware-Target Unaware condition (i.e., judge aware of judging and target unaware of being judged), participants were informed before the interaction that they would be asked to 'judge their interaction partner's personality' after the interaction but that their interaction partner would not be asked to judge them. In reality, their interaction partner was given the same instructions so that both participants were aware of judging their partner, but unaware that they were being judged themselves. Finally, in the Judge Unaware-Target Unaware condition (i.e., judge unaware of judging and target unaware of being judged), participants were given no further information. In the latter two conditions, upon conclusion of the interaction, participants were immediately informed of the true nature of the study (i.e., that it is interested in personality judgements) and asked if they were happy to continue with the study, which they indicated by signing an additional consent form. Participants who received the full information about the purpose of the study were asked not to reveal this information to their interaction partner. All participants were assured of the confidentiality of their ratings and the study has been ethically approved by the Psychology Department's Research Ethics Committee. 


\section{Results}

\subsection{Preliminary analyses}

\subsubsection{Trait IM}

To examine whether self-reported IM was contributing to the experimental effect, target participants' self-reported IM was collected before the experimental manipulation. A one-way ANOVA revealed no significant differences in self-reported IM across condition, all $F s<1$, all $\eta_{\mathrm{p}}^{2}<.06$. As a manipulation check, after the experiment all participants were asked if they were aware that they would be asked to make a judgement and whether they were aware that they would be judged themselves by indicating 'yes' or 'no'. No participants reported awareness of judging/being judged, with the exception of all participants in the fully informed condition (i.e., Judge-Aware-Target Aware).

\subsubsection{Analytic strategy}

Accuracy was assessed as the correlation between targets' composite personality scores (i.e., mean of the self and informant ratings) and scores rendered by judges for interpersonal and less interpersonal traits ${ }^{1}$ using the item approach. Specifically, accuracy scores were first computed by item then transformed into Fisher- $z$ coefficients, which are normally distributed, and were then subject to an ANOVA and results were converted back into $r$ for presentation.

Dyad members served as both a target and a judge ${ }^{2}$; therefore, there were 88 judges and 88 targets as each person was treated as a judge. As the potential for non-independence was created intraclass correlations (ICC) were computed at both the individual and aggregate level (Shrout \& Fleiss, 1979) for each trait. A one-way random effects model revealed a mean ICC of .11 (range .02 to .22). As no ICC exceeded 3 individually or in the aggregate, analyses were computed with individual participants as the unit of analysis (see Kenny, 1995, Table 4; Kurtz \& Sherker, 2003).

The item approach was deemed appropriate as it correlates scores across persons rendering as many correlations as there are items. An advantage of this approach is that it removes problems associated with stereotype accuracy (i.e., the tendency to rate the mean trait; see Funder, 1999; Letzring et al., 2006). Although it has been argued that such an approach may be confounded by differential accuracy, this should not be a problem for the present study as relative accuracy, not absolute accuracy, is examined (see Cronbach, 1955; Letzring, 2008).

\subsection{Interaction demands and judgement accuracy}

Table 1 displays the mean accuracy scores for interpersonal and less interpersonal traits as a function of interaction demand.

A 3 (interaction demand: Judge Aware-Target Aware, Judge AwareTarget Unaware, Judge Unaware-Target Unaware) $\times 2$ (trait type: Interpersonal, Less-interpersonal) mixed ANOVA revealed a main effect of interaction demand, $F(2,52)=5.22, p<.01, \eta_{\mathrm{p}}^{2}=.17,95 \% \mathrm{CI}[.13, .19]$. Thus, as predicted $(\mathrm{H} 1)$, variations in interaction demand had a significant effect on judgement accuracy. Although no specific predictions were made regarding the direction of effects for overall accuracy (i.e., across trait type) post hoc comparisons with Bonferroni adjustments revealed that mean accuracy was higher in the Judge Unaware-Target Unaware condition $(M=.21, S E=.02)$ than the Judge Aware-Target Unaware condition $(M=.11, S E=.02), p<.01$ (all other comparisons were nonsignificant, $p s>.05$ ). These findings suggest that when target and judge demands are equivalent, specifically in terms of not knowing that any

\footnotetext{
${ }^{1}$ As openness has been referred to as one of the most difficult traits to conceptualise (Dennis, Masthoff, \& Mellish, 2012; Digman, 1990) this trait was not included in analyses that focus on interpersonal and less interpersonal traits.

2 Although a more conservative approach accuracy correlations needed to be computed at the item level and not the trait level as this would only have produced 5 scores per condition - one for each trait. This would not have produced sufficient cell data for univariate analysis to be performed.
}

judgement is required, accuracy appears to improve relative to when only one person is aware of making a judgement. This finding suggests that accuracy is not solely related to targets interaction demands, but also relates to the judges interaction demands or lack thereof. To gain a more nuanced understanding it is imperative to explore the findings by trait type.

\subsection{Interaction demands and accuracy by trait type}

The second hypothesis was that variations in interaction demands will significantly impact on judgement accuracy for the less interpersonal traits of conscientiousness and neuroticism. This was supported as a significant interaction effect was found between interaction demand and trait-type, $F(2,52)=3.39, p<.05, \eta_{p}^{2}=.12$. As no specific predictions were made about which condition would positively shape accuracy, given the previous lack of research, post hoc tests were performed (with Bonferroni adjustments) and revealed that accuracy for less interpersonal traits was higher in the Judge Unaware-Target Unaware condition than in the Judge Aware-Target Unaware $(p=.004)$ (i.e., Condition 1 vs. Condition 2; see Table 1 ). This finding suggests that when targets and judges have different interaction demands accuracy for less interpersonal traits was lower than when judge and target demands are equivalent in terms of both target and judge 'knowing' that a judgement is required.

The post hoc tests also revealed that the difference in accuracy for less interpersonal traits in the Judge Unaware-Target Unaware condition $(M=.24, S E=.03)$ were not significantly different to accuracy for those traits in the Judge Aware-Target Aware condition $(M=.13$, $S E=.03$ ), $p<.10$ (i.e., Condition 1 vs. Condition 3; see Table 1).

Further post hoc tests for the significant interaction effect revealed that interpersonal traits were judged more accurately $(M=.16, S E=$ $.03)$ than less interpersonal traits $(M=.06, S E=.03)$ when judges were aware of making a judgement but unaware of being judged (i.e., a within condition effect) $(p=.01)$. All other comparisons between interpersonal and less interpersonal traits within the Judge UnawareTarget Unaware condition $(p>.05)$ and the Judge Aware-Target Aware condition $(p>.05)$ were not significant. Interestingly, this suggests that when targets and judges have different interaction demands accuracy is negatively affected for less interpersonal traits relative to interpersonal traits. Results for each Big-5 trait are reported in the Supplementary materials.

Finally, although no specific predictions were made for judgement accuracy of interpersonal traits across interaction condition, post hoc tests (with Bonferroni adjustments) revealed that interpersonal traits were rated with similar levels of accuracy across all conditions as no significant differences in accuracy were found $(p>.05)$.

Although participants were not asked about differences in cognitive load they were asked, at the end of the study, how accurately they felt that they perceived their partner's personality. A one-way ANOVA with condition as the IV and perception of accuracy as the DV found a non-significant difference across conditions, $F(2,84)=1.09, p>.05$, $\eta_{\mathrm{p}}^{2}=.09$ suggesting that judges felt equally accurate in their judgement regardless of interaction demand. All effect sizes reported $\left(\eta_{\mathrm{p}}^{2}\right)$ are small (see footnote 3).

\section{Discussion}

The present study sought to examine the impact of target and judge interaction demands on judgement accuracy. Given that no previous research, to the best of our knowledge, has explored Big-5 judgement accuracy in contexts where people are unaware that a judgement task is involved relative to when people are aware that a judgement is involved, the findings offer a fruitful contribution to the accuracy and impression management literatures.

One interesting pattern of results that emerged was the role that a mismatch in interaction demands placed on judges and targets had on 
Table 1

Mean accuracy correlations as a function of interaction condition and trait type.

\begin{tabular}{|c|c|c|c|}
\hline \multirow[t]{2}{*}{ Judgement accuracy } & Condition 1 & Condition 2 & Condition 3 \\
\hline & Judge Unaware-Target Unaware & Judge Aware-Target Unaware & Judge Aware-Target Aware \\
\hline Interpersonal traits & $.19(.14)$ & $.16(.12)^{2}$ & $.20(.09)$ \\
\hline Less interpersonal traits & $.24(.12)^{1}$ & $.06(.13)^{12}$ & $.13(.14)$ \\
\hline
\end{tabular}

Note. $S D$ is in parentheses - figures in superscript denote the values that were significantly different.

accuracy. In terms of overall accuracy across trait type, poorer accuracy was found when target-judge interaction demands differed compared to when these demands were equivalent. This difference was only found to be significant when compared to the context where interaction demands were equivalent in terms of not knowing that a judgement was required. However, findings indicated that in those conditions where judge and target demands were equivalent no difference in accuracy was found between interpersonal and less interpersonal traits. However, in the context in which interaction demands differed interpersonal traits were judged significantly more accurately than less interpersonal traits $(p<.01)$ as a significant within context effect was found.

Interpersonal traits were judged with similar levels of accuracy in all conditions. Although speculative, one possible explanation is that judges focus closely on interpersonal traits in an interaction. This is supported by Funder's $(1995,1999,2012)$ realistic accuracy model, which posits that judge motivation can impact on the detection and utilisation of behavioural cues when rating others. One possible explanation for why judges may focus on interpersonal traits relates to the notion that these traits are functional within an interpersonal context (Ames \& Bianchi, 2008). The present findings corroborate this differential trait focus and indicate that the task demands placed on targets and judges appear to shape accuracy in specific ways. Given the nature of any first impression encounter it is not surprising that interpersonal traits may be the traits that people focus on when rating another's personality, as knowing whether someone will be talkative (i.e., a facet of extroversion) and be friendly (i.e., a facet of agreeableness) are arguably more relevant during an initial encounter than knowing whether someone is emotionally stable (i.e., a facet of neuroticism) and dependable (i.e., a facet of conscientiousness) (see McLarney-Vesotski, Bernieri, \& Rempala, 2006). This explanation may also account for why judgement of interpersonal traits did not differ significantly across interaction conditions; accuracy for interpersonal traits did not operate as a function of condition but due the functional nature of attending to the relevant cues, however, judgement of the less interpersonal traits was hindered when judgement demands differed. Thus, these findings corroborate literature on enhanced accuracy for observable traits such as extroversion and reduced accuracy for neuroticism (e.g., Albright et al., 1988; Watson, 1989).

The relationship between the accuracy of judgements for less interpersonal traits and interaction condition is not simple. The within context finding that less interpersonal traits were rated less accurately than interpersonal traits when target-judge demands varied ( $p=$ .004) suggests that accuracy for traits such as conscientiousness and neuroticism may be more negatively affected by interaction condition than accuracy for interpersonal traits. This difference in accuracy is difficult to account for, as there is little evidence to suggest that it was due to target performance. Funder's (1995) RAM suggests that target provision of accurate and relevant cues can impact on judgement accuracy, yet in the current study there is no reason to believe that the cues for less interpersonal traits differed between the Judge Aware-Target Unaware condition and the Judge Unaware-Target Unaware condition, in which the greatest level of accuracy was found, at a descriptive level (see Table 1). In fact, both conditions in which the target and judge faced equivalent demands resulted in less interpersonal traits being judged as accurately as interpersonal traits. As the pattern of results observed cannot be explained solely through the interaction demands of the judge nor those of the target we suggest that they arise as a result of the interaction between both judge and target motivations and behaviours. We acknowledge that this suggestion is tentatively made but feel that, in the context of our findings, it is reasonable and justifies further investigation of a previously unexplored issue. As noted by Funder $(1995,1999)$ - the best judge in the world cannot make an accurate judgement if valid cues are not revealed by the target - the present study suggests that when judges are also targets and interaction demands differ, detection may be hampered for less interpersonal traits.

In relation to Patterson's (1995) parallel process model, how we present ourselves to others is only part of an interpersonal interaction and our judgements of others are also important to consider. The present findings suggest that these differences are relevant for differences in accuracy in terms of the type of trait concerned and warrant further investigation. Indeed, a possible explanation is that the effect observed here is primarily driven by judge awareness, as accuracy in the Judge AwareTarget Aware condition was also (marginally) lower than accuracy in the Judge Unaware-Target Unaware condition. Thus, it may just be that awareness of having to form a judgement enhances cognitive load, which could both hinder the judge's ability to form accurate judgements and also lead them to provide less useful information as a target.

\subsection{Limitations and future directions}

When comparing the moderate to low effect sizes reported herein to other research some studies have reported similar results. For example, research by Back et al. (2008) into personality judgements based on an email address reports accuracy correlations ranging from .05 to .13. A review by Hall, Andrzejewski, Murphy, Mast, and Feinstein (2008) reported average accuracy for face to face studies $(r=.23)$. In the present study accuracy correlations ranged from .06 to .18. The small effect sizes obtained are likely, in part, due to the more conservative analytical approach adopted. ${ }^{3}$ The significant findings obtained using this approach arguably limit the possibility of a type one error and warrant further research. Indeed, given the complexities in real life dyadic interaction it is intriguing that significance was observed and good reliability of judges' ratings supports this, to some degree.

When considering the generalisability of the findings it is important to acknowledge that the sample comprised of undergraduate students, with little variation in ethnicity. Therefore, it would be useful for future research to examine a more representative sample. Indeed, it would be interesting to examine whether cultural differences impact on the pattern of findings observed here. Related to this suggestion it would be interesting for future studies to incorporate a measure of self-monitoring behaviour (i.e., sensitivity to social cues and ability to modify self-presentation; Snyder, 1974) so as to develop the theoretical contribution of the findings further.

A strength of the present research was the focus on 'real' people in 'real' (i.e., non-laboratory) contexts, which Funder's (1999) acknowledges

\footnotetext{
${ }^{3}$ Mean accuracy across trait and condition using summed scale scores across person and item (i.e., one correlation per trait per condition) produced a value of .33. Importantly, the pattern of findings was the same and suggests that the present set of results using the item approach is more conservative.
} 
is crucial for accuracy research as it enhances the generalisability of the findings.

\subsection{How can these findings be used?}

The findings of the current paper suggest that the demands within a judgement task need to be equivalent and that one must be particularly cautious when judging people in contexts where self-presentation demands vary, as one is likely to form a less accurate impression for less interpersonal traits. A likely scenario is the assessment of a potential future date where one person interacts with another knowing that they are judging them as a potential partner whereas the other is oblivious that the interaction is anything other than an initial first encounter.

As noted in Patterson's (1995) parallel process model, important subtleties are involved in interpersonal interactions shaped by goals and expectancies. Our data indicates that we need to get the balance right in terms of managing our own behaviour and impressions of another, as evident in a differential pattern of accuracy for interpersonal and less interpersonal traits.

Supplementary data to this article can be found online at http://dx. doi.org/10.1016/j.paid.2015.08.037.

\section{Declaration of conflicting interest}

The author declares no potential conflicts of interest with respect to the research, authorship, and/or publication of this article.

\section{Funding}

No funding was sought for this research.

\section{References}

Akert, R. M., \& Panter, A. T. (1988). Extraversion and the ability to decode nonverba communication. Personality and Individual Differences, 9, 965-972. http://dx.doi.org/ 10.1016/0191-8869(88)90130-4.

Albright, L., Kenny, D. A., \& Malloy, T. E. (1988). Consensus in personality judgments at zero-acquaintance. Journal of Personality and Social Psychology, 55, 387-395. http:// dx.doi.org/10.1037/0022-3514.55.3.387.

Ames, D. R., \& Bianchi, E. (2008). The agreeableness asymmetry in first impressions: Perceivers' impulse to (mis)judge agreeableness and how it is moderated by power. Personality and Social Psychology Bulletin, 34, 1719-1736. http://dx.doi.org/10.1177/ 0146167208323932

Argyle, M., Martin, M., \& Crossland, J. (1989). Happiness as a function of personality and social encounters. Recent advances in social psychology: An international perspective, 189-203.

Ashton, M. C., \& Lee, K. (2005). Honesty-humility, the Big Five, and the Five Factor Model. Journal of Personality, 73, 1321-1353. http://dx.doi.org/10.1111/j.14676494.2005.00351.

Back, M. D., Schmukle, S. C., \& Egloff, B. (2008). How extraverted is honey.bunny77@hotmail. de? Inferring personality traits from email addresses. Journal of Research in Personality, 42, 1116-1122. http://dx.doi.org/10.1016/j.jp.2008.02.001.

Barrick, M. R., \& Mount, M. K. (1996). Effects of IM and self-deception on the predictive validity of personality constructs. Journal of Applied Psychology, 81(3), 261-272. http://dx.doi.org/10.1037/0021-9010.81.3.261.

Baumeister, R. F. (1982). A self-presentational view of social phenomena. Psychological Bulletin, 91, 3-26.

Beer, A., \& Watson, D. (2008). Asymmetry in judgments of personality: Others are less differentiated than the self. Journal of Personality, 76(3), 535-560.

Berry, D. S., \& Hansen, J. S. (2000). Personality, nonverbal behavior, and interaction quality in female dyads. Personality and Social Psychology Bulletin, 26(3), 278-292.

Biesanz, J. C., \& Human, L. J. (2010). The cost of forming more accurate impressions: Accuracy-motivated perceivers see the personality of others more distinctively but less normatively than perceivers without an explicit goal. Psychological Science, 21(4), 589-594. http://dx.doi.org/10.1177/0956797610364121.

Blackman, M. C., \& Funder, D. C. (2002). Effective interview practices for accurately assessing counterproductive traits. International Journal of Selection and Assessment, $10(1 / 2), 109-116$.

Bolino, M. C., \& Turnley, W. H. (1999). Measuring IM in organizations: A sale development based on the Jones and Pittman taxonomy. Organizational Research Methods, 2 , 187-206. http://dx.doi.org/10.1002/job.185.

Bolino, M. C., Varela, J. A., Bande, B., \& Turnley, W. H. (2006). The impact of impressionmanagement tactics on supervisor ratings of organizational citizenship behaviour. Journal of Organizational Behaviour, 27, 281-297.
Borkenau, P., \& Liebler, A. (1992). Trait inferences: Sources of validity at zero acquaintance. Journal of Personality and Social Psychology, 62, 645-657. http://dx.doi.org/10. 1037/0022-3514.62.4.645.

Buchanan, T., Johnson, J. A., \& Goldberg, L. (2005). Implementing a Five-Factor personality inventory for use on the internet. European Journal of Psychological Assessment, 21, 115-127. http://dx.doi.org/10.1027/1015-5759.21.2.115.

Cronbach, L. J. (1955). Processes affecting scores on understanding of others and assumed similarity. Psychological Bulletin, 52, 177-193.

Dennis, M. G., Masthoff, J., \& Mellish, C. S. (2012). Adapting performance feedback to a learner's conscientiousness. Proceedings of user modeling, adaptation, and personalization. 20th International Conference, UMAP 2012, 16-20 July. (pp. 297-302). Montreal, Canada: Springer-Verlag. http://dx.doi.org/10.1007/978-3-642-31454-4_25.

Digman, J. M. (1990). Personality structure: Emergence of the Five-Factor Model. Annual Review of Psychology, 41(1), 417-440.

Ellis, A. P. J. West, B. J.. Ryan, A. M., \& DeShon, R. P. (2002). The use of impression management tactics in structured interviews: A function of question type. Journal of Applied Psychology, $87,1200-1208$

Forrest, J. A., \& Feldman, R. S. (2000). Detecting deception and judge's involvement: Lower task involvement leads to better lie detection. Personality and Social Psychology Bulletin, 26(1), 118-125.

Funder, D. C. (1995). On the accuracy of personality judgment: A realistic approach. Psychological Review, 102, 652-670. http://dx.doi.org/10.1037/0033-295X.102.4.652.

Funder, D. C. (1999). Personality judgment: A realistic approach to person perception. San Diego, CA: Academic Press.

Funder, D. C. (2012). Accurate personality judgment. Current Directions in Psychological Science, 21(3), 177-182.

Funder, D. C., \& Colvin, C. R. (1988). Friends and strangers: Acquaintanceship, agreement, and the accuracy of personality judgment. Journal of Personality and Social Psychology, $55,149-158$.

Funder, D. C., \& Dobroth, K. M. (1987). Differences between traits: Properties associated with interjudge agreement. Journal of Personality and Social Psychology, 52(2), 409. http://dx.doi.org/10.1037/0022-3514.52.2.409.

Gill, A. J., \& Oberlander, J. (2003). Perception of e-mail personality at zero-acquaintance: Extraversion takes care of itself, but neuroticism is a worry. Proceedings of the 25th Annual Conference of the Cognitive Science Society, Boston, MA, August 2003 (pp. 456-461).

Gilmore, D. C., \& Ferris, G. R. (1989). The effects of applicant impression management tactics on I. Journal of Management, 15(4), 557.

Goldberg, L. R., Johnson, J. A., Eber, H. W., Hogan, R., Ashton, M. C., Cloninger, C. R., \& Gough, H. G. (2006). The International Personality Item Pool and the future of public-domain personality measures. Journal of Research in Personality, 40, 84-96. http://dx.doi.org/ 10.1016/j.jrp.2005.08.007.

Gosling, S. D., Ko, S. J., Mannarelli, T., \& Morris, M. E. (2002). A room with a cue: Judgments of personality based on offices and bedrooms. Journal of Personality and Social Psychology, 82, 379-398.

Hall, J. A., Andrzejewski, S. A., Murphy, N. A., Mast, M. S., \& Feinstein, B. A. (2008). Accuracy of judging others' traits and states: Comparing mean levels across tests. Journal of Research in Personality, 42, 1476-1489.

Hall, J. A., Blanch, D. C., Horgan, T. G., Murphy, N. A., Rosip, J. C., \& Schmid Mast, M. (2009). Motivation and interpersonal sensitivity: Does it matter how hard you try? Motivation and Emotion, 33(3), 291-302. http://dx.doi.org/10.1007/s11031-009-9128-2.

Human, L. J., \& Biesanz, J. C. (2012). Accuracy and assumed similarity in first impressions of personality: Differing associations at different levels of analysis. Journal of Research in Personality, 46, 106-110. http://dx.doi.org/10.1016/j.jrp.2011.10.002.

Human, L. J., Biesanz, J. C., Parisotto, K. L., \& Dunn, E. W. (2012). Your best self helps reveal your true self: Positive self-presentation leads to more accurate personality impressions. Social Psychological and Personality Science, 3(1), 23-30. http://dx.doi.org/10. $1177 / 1948550611407689$.

Ickes, W., Gesn, P. R., \& Graham, T. (2000). Gender differences in empathic accuracy: Differential ability or differential motivation? Personal Relationships, 7, 95-109. http://dx.doi. org/10.1111/j.1475- 6811.2000.tb00006.x.

Jamieson, J. P., \& Harkins, S. G. (2007). Mere effort and stereotype threat performance effects. Journal of Personality and Social Psychology, 93, 544-564.

Kacmar, K. M., Carlson, D. S., \& Brymer, R. A. (1999). Antecedents and consequences of organizational commitment: A comparison of two scales. Educational and Psychological Measurement, 59(6), 976-994.

Keltner, D., Gruenfeld, D. H., \& Anderson, C. A. (2003). Power, approach, and inhibition. Psychological Review, 110, 265-284.

Kenny, D. A. (1995). The effect of nonindependence on significance testing in dyadic research. Personal Relationships, 2(1), 67-75.

Klein, K. J., \& Hodges, S. D. (2001). Gender differences, motivation, and empathic accuracy: When it pays to understand. Personality and Social Psychology Bulletin, 27(6), 720-730.

Kurtz, J. E., \& Putnam, S. H. (2006). Patient-informant agreement on personality ratings and self-awareness after head injury. Clinical Neuropsychology, 20, 453-468. http:// dx.doi.org/10.1080/13854040590967090.

Kurtz, J. E., \& Sherker, J. L. (2003). Relationship quality, trait similarity, and self-other agreement on personality ratings in college roommates. Journal of Personality, 71(1), $21-48$.

Leary, M. R., \& Kowalski, R. M. (1990). Impression management: A literature review and two-component model. Psychological Bulletin, 107(1), 34. http://dx.doi.org/10.1037/ 0033 2909.107.1.34

Letzring, T. D. (2005). Personality and behavioural correlates of accurate personality judgment. Unpublished doctoral dissertation, University of California

Letzring, T. D. (2008). The good judge of personality: Characteristics, behaviours, and observer accuracy. Journal of Research in Personality, 42, 914-932. http://dx.doi.org/ 10.1016/j.jrp.2007.12.003. 
Letzring, T. D., Wells, S. M., \& Funder, D. C. (2006). Information quantity and quality affect the realistic accuracy of personality judgment. Journal of Personality and Social Psychology, 91http://dx.doi.org/10.1037/0022-3514.91.1.111.

Markey, P. M., \& Wells, S. M. (2002). Interpersonal perception in internet chat rooms. Journal of Research in Personality, 36, 134-146. http://dx.doi.org/10.1006/jrpe.2002. 2340.

McLarney-Vesotski, A. R., Bernieri, F., \& Rempala, D. (2006). Personality perception: A developmental study. Journal of Research in Personality, 40, 652-674.

Murphy, N. A. (2007). Appearing smart: The IM of intelligence, person perception accuracy, and behaviour in social interaction. Personality and Social Psychological Bulletin, 33(3), 325-339.

Naumann, L. P., Vazire, S., Rentfrow, P. J., \& Gosling, S. D. (2009). Personality judgments based on physical appearance. Personality and Social Psychology Bulletin, 35(1), 1661-1671.

Ones, D. S., \& Viswesvaran, C. (1998). The effects of social desirability and faking on personality and integrity assessment for personnel selection. Human Performance, 11(2-3), 245-269.

Patterson, M. L. (1995). Invited article: A parallel process model of nonverbal communication. Journal of Nonverbal Behavior, 19(1), 3-29.

Patterson, M. L., Churchill, M. E., Farag, F., \& Borden, E. (1991). Impression management, cognitive demand, and interpersonal sensitivity. Current Psychology, 10(4), 263-271.

Patterson, M. L., \& Stockbridge, E. (1998). Effects of cognitive demand and judgment strategy on person perception accuracy. Journal of Nonverbal Behavior, 22(4), 253-263.

Paulhus, D. L., Bruce, M. N., \& Trapnell, P. D. (1995). Effects of self-presentation strategies on personality profiles and their structure. Personality and Social Psychology Bulletin, 21(2), 100-108. http://dx.doi.org/10.1177/0146167295212001.

Rodriguez-Bailon, R., Moya, M., \& Yzerbyt, V. (2000). Why do superiors attend to negative stereotypic information about their subordinate? Effects of power legitimacy on social perception. European Journal of Social Psychology, 30, 651-671.
Rudman, L. A. (1998). Self-promotion as a risk factor for women: The costs and benefits of counter stereotypical impression management. Journal of Personality and Social Psychology, 74, 629-645.

Schlenker, B. R., \& Weigold, M. F. (1989). Goals and the self-identification process. In L. Pervin (Ed.), Goals concepts in personality and social psychology (pp. 243-290). Hillsdale, NJ: Erlbaum.

Shrout, P. E., \& Fleiss, J. L. (1979). Intraclass correlations: uses in assessing rater reliability. Psychological bulletin, 86(2), 420.

Snodgrass, S. E. (1985). Women's intuition: The effect of subordinate role on interpersonal sensitivity. Journal of Personality and Social Psychology, 49(1), 146.

Snyder, M. (1974). Self-monitoring of expressive behavior. Journal of Personality and Social Psychology, 30(4), 526.

Snyder, M., \& Swann, W. B. (1976). When actions reflect attitudes: The politics of impression management. Journal of Personality and Social Psychology, 34(5), 1034-1042. http://dx.doi.org/10.1037/0022-3514.34.5.1034.

Swann, W. B. (1984). Quest for accuracy in person perception: A matter of pragmatics. Psychological Review, 91(4), 457.

Vohs, K. D., Baumeister, R. F., \& Ciarocco, N. J. (2005). Self-regulation and self-presentation: Regulatory resource depletion impairs impression management and effortful selfpresentation depletes regulatory resources. Journal of Personality and Social Psychology, 88, 632-657.

Wall, H. J., Taylor, P. J. Dixon, J. Conchie, S. M., \& Ellis, D. A. (2013). Rich contexts do not always enrich the accuracy of personality judgments. Journal of Experimental Social Psychology, 49, 1190-1195. http://dx.doi.org/10.1016/j.jesp.2013.05.010.

Watson, D. (1989). Strangers' ratings of the five robust personality factors: Evidence of surprising convergence with self-report. Journal of Personality and Social Psychology, 57(1), 120. 